\title{
A Model for Detection and Prevention of Unbalanced Bid in the Public Work Procurement Process in India
}

\author{
Ms. Richa Chouksey ${ }^{1}$, Salman Khursheed ${ }^{2}$, Kuldeep Kumar ${ }^{3}$ \\ ${ }^{1}$ Post Graduate Student, ${ }^{2}$ Assistant Professor, ${ }^{3} \mathrm{Ph}$.D. Scholar \\ ${ }^{1}$ Building Engineering and Management Department \\ ${ }^{1}$ School of Planning and Architecture, Delhi, India
}

\begin{abstract}
Indian Public procurement works contribute almost 30\% of the total GDP, most of the large and massively funded projects are public funded, utilizing the tax collected from the citizens of the country. Hence, any discrepancies associated with such projects has direct implication on the tax payers. Public procurement process, due to legal bindings and ethics are prone to various malpractices, that affect the overall performance of the system. Hence, it becomes imperative to prevent anomalies associated with thepublic procurement process. One of the anomalies associated with public procurement is Unbalanced bid, a method of redistributing the project cost such that it varies from Engineer's Estimate. The ethics related to Unbalanced bid varies, contractors state that unbalanced bidding is moral and find its application beneficial to the project performance while clients and officials opine that unbalanced bid is an unethical practice to jeopardize project progress and client's money. The unbalanced bid can be of four types - Quantity Error Exploitation, Front loaded Bid, Back loaded Bid and Collusive bid. The research intends to propose a model to detect and prevent unbalanced bid respecting the constraints of public procurement process in India, enhancing project performance and protecting tax payer's money.
\end{abstract}

KEYWORDS: Unbalanced Bid, Indian Public Procurement, Prevention and Detection model, Unbalanced bidding model

\section{INTRODUCTION}

Indian Public Procurement System constitutes $30 \%$ of the GDP of India. While Departments like Indian Railways, Telecom, etc. contributes $50 \%$ of their budget for procurement, establishing a competitive conduct is important for procurement process to ensure efficient use of public money, national security and for quality infrastructure and services (Malhotra, 2012).

In Indian public procurement, selection of contractor for work execution is based on L1 selection method, traditionally. The selection is majorly dependent on the value of bid alongwith certain pre-qualification criteria that must be assured by the bidder to be an eligible. The decision making strictly adheres to the guidelines of procurement process, but there are certain deficiencies that are taken advantage of, by the bidder to get through the procurement process causing disputes, cost escalation or schedule overrun during execution (Paul \& Seth, 2017).

In this context, (Mittal, et al., 2020) has highlighted several aspects regarding the past studies find Unbalanced Bidding as one of the major factors that makes it difficult to find a potential bidder, wherein the premise was supported by the example of infrastructure projects.

It is important to develop a model which works within the set boundaries of Indian procurement system, at the same time efficient of identifying minute or not so obvious unbalanced bids aswell. (Gopikrishnan \& Paul, 2018) in their study revealed the vital factors that affects the project cost in government residential buildings. In addition, (Mittal, et al., 2019) highlighted the significance of preventing the anomalies associated with the public procurement process in Indian scenario especially pertaining to the infrastructure projects. Also, a set mechanism for calculation of additional deposits or forecasting of possible risk will help improve the procurement system performance against unbalanced bid besides avoiding disputes too.

The aim of the research is to develop a model for detection and prevention of unbalanced bid in the public work procurement process in India.

The objectives of the research are-

1. To analyze various models and methods for prevention and detection of unbalanced bid and models for formulating unbalanced bid to identify factors affecting unbalanced bid.

2. To prepare a model for prevention and detection of unbalanced bid to deal with Front-loaded, Back-loaded and Quantity Error Exploitation unbalanced bid.

3. To illustrate the proposed model for detection and prevention of unbalanced bid in the public work 
procurement process in India, by applying it to a case study project.

The methodology adopted was to study various existing models for quoting unbalanced bidding and prevention of unbalanced bid by various authors to know the perspective of both owner and contractor. Based on the study various variables were identified and a framework for detection and prevention of unbalanced bid was formulated using Excel as the tool, which was further illustrated using case study.

\section{UNBALANCED BID}

(ASIAN DEVELOPMENT BANK, 2018) defines unbalanced bid as when the item rate quoted in the bid is exceptionally high compared to Engineer's estimate as well as otherbidders while (Manzo, 1997) defines unbalanced bid as shifting cost of work from one element to another element. Standards define unbalanced bid as a deviation from Engineer's Estimate, authors define unbalanced bid as a mathematicaltool to determine the optimum distribution of prices to be applied to a project's component items when engaging in competitive bidding (CATTELL, et al., 2010) or as intentional manipulation of price distribution in a bid proposal by the contractor with the purpose to exploit related advantages (Polat, et al., 2019) (David W. Cattell, 2007). According to (Paul, et al., 2017), procurement process, due to legal bindings and ethics are prone to various malpractices, that affect the overall performance of the system. Generally, the contractor practices unbalancing to ensure smooth cashflow and risk reduction, but it's a disadvantage to the client as the project may suffer cash crunch, abandoning by the contractor or escalated cost ofthe project.

An unbalanced bid can be either mathematically unbalanced or materially unbalanced. A mathematically unbalanced bid is a bid that contains some line item's unit price determined to be significantly overstated or under- stated (ARDITI \& CHOTIBHONGS, 2009), the objective of bid unbalancing is to maximize the present worth of the payments by changing the bid prices for the different items within acceptable limits and at the same time keeping the bid price equal to that of the balanced bid (Nassar, 2003) while materially unbalanced bid is a bid which included overprizing or underpricing of items which are subject to increase or decrease during execution respectively. Sub category of unbalanced bid areQuantity Error Exploitation, Front-End loading, Back End Loading and Collusive Bid unbalancing (Prajapati \& Bhavsar, 2017).

\subsection{Quantity Error Exploitation}

Quantity Error Exploitation, which is also termed as 'individual rate loading' is a practice for unbalancing, taking advantage of the Engineer's error in quantity calculation of items in the BOQ. This process entails loading the price of items whose final quantities are expected to exceed the initial quantities contained in the tender documentation (David W. Cattell, 2007). This concept is based on a situation where the contractor is more informed than the client.

- Quantity Error bid may lead to rejection of true responsive bid

- Such bidding practice will eventually lead tocost escalation of the project

\subsection{Collusive Bid Unbalancing}

Collusive Bid Unbalancing is an unethicalpractice where an officer from the employer's organization colludes with the bidder and provides them with the information related to the tender items subject to change during execution. As a result, the bidder manipulates the item ratesin the bid to be the lowest without compromising the profit (Prajapati \& Bhavsar, 2017).

\subsection{Front Loading}

Front loading is price loading of items to beexecuted in early stage of construction that will improve contractor's cashflow (David W. Cattell,2007). Front loading is widely practiced on unit price contracts (Nassar, 2003).

Risk to the owner:

1. The contractor might default the project after receiving advance payment (Kenley, (2003) leaving client with an interim overpaid project and little possibility to find another bidder willing to work with left overlimited funds (Skitmore \& Cattell, 2013).

2. The advance payment passively causes morecost to the owner (Hyari, 2017).

3. Reducing contractor's motivation to complete project as later stages of execution could be undervalued (Hyari, 2017).

4. Cause delay to the project as by the later phase the contractor and client both might run out of budget for the project (Kenley, (2003).

5. Invalid advantage to be the least bidder (Hyari, 2017); (Kenley, (2003).

6. Difficulty in tracking the progress of the project as the whole cashflow is disturbed.

Reduced risk at contractor's end:

1. Reduces negative impact of delayed payment by the employers to the contractor (Christodoulou, 2009).

2. Ensures smooth cash flow cycle throughout project execution.

\subsection{Back Loading}

Back-end loading is a contrary case of front-end loading where the items to be executed in the later stages of execution are overloaded to take advantage of the higher rate of escalation. Such practices area more common for project withlonger duration (Polat, et al., 2019).

\section{INDIAN PROJECT PROCUREMENT}

Front loaded bid and Quantity error exploitation are two common unbalancing followed widely. Indian procurement 
"A Model for Detection and Prevention of Unbalanced Bid in the Public Work Procurement Process in India"

tackles identify cost variancefrom the Engineer's Estimate and safe guard their interest by charging nominal additional fee to performance guarantee.

Challenges in identification of unbalanced bid

1. Bids are realized to be unbalanced post execution.

2. Detection of unbalanced bid can be timeconsuming.

3. Reliability on the price variation technique for detecting unbalanced bid, which isefficient to detect obvious unbalancing only.

4. The performance deposit claimed and its refund may lead to disputes.

5. (Skitmore \& Cattell, 2013) the balanced bidsare often incorrectly detected as unbalanced.

Constraints and requirements were identified in Indian Procurement. The constraints found were:

1. It is difficult to reject an unbalanced bid ifits an L1 bidder. The only way out is to charge additional amount in the performancebid.

2. The procurement system is rigid, and themodel has to be developed within theboundaries of the process.

3. Payment reimbursement from government organizations is a cumbersome process and might require, 2-3 months, another reason for bidders to unbalance their bid.

The requirements comprehended were:

1. Prevention and identification of unbalanced bid in India depends upon deviation of $5 \%$ in item cost and charging security deposit.

2. There is no existing guideline or model for calculating additional charges, if the L1 bid is found unbalanced.

3. If the bid is found unbalanced or abnormallylow, a clarification is called for from the identified L1 bidder which may result to false promises for the sake of procuring project.

4. Existing models considers sequential execution of individual items whereas thepayments done are either as per the stages ofprogress or fixed installments as and when raised by the contractor during execution.

\section{PREVENTION AND DETECTIONMODEL}

\subsection{Grading System-based Model}

(Polat, et al., 2019) proposed a model based ongrading system to detect unbalanced bid-Compares the ratio of each activity's price byeach bidder with the estimated one; comparesunit price of each activity by each bidder with the ones estimated by the owner; compares unit price of each activity by each bidder with the average of unit prices by $\mathrm{n}$ number of bidders; compares the bid price offered by the bidderwith the estimated construction cost; comparethe sum of total prices of quantities likely increase during the construction by bidders with the ones estimated by the owner.

Bidders obtain grades according to these ratios and highest rank is selected.

\subsection{Evaluation Model for Unbalanced Bid}

(Sake Venkatesh1, 2017) proposed a model to focus on quantity error exploitation and early payments. The model includes calculation of theexpected upper and lower bound on the quantity and unit price variations based on upper and lower percentages of deviations or with some fixed boundaries. It includes calculation of the total value of the projects based upon the presentvalue and hence identify the true L1, the one who expects least profit.

\subsection{David Arditi and Ranon Chotibhongs}

(ARDITI \& CHOTIBHONGS, 2009) proposed two separate model for front loading and quantity error exploitation detection based onlogic using excel as the tool. The two models compare bid's item individually with Engineer's estimate and the average of the bids and hence detect the least bidder with minimum NPV. The limitation was the missing guideline for the four parameters - the accepted difference from the engineer's estimate; the accepted difference from the average line-item prices; the proportionof the project that describes 'early' schedule; and the discount rate.

\subsection{A Risk-Based Approach}

(Hyari, 2016) proposed a model based on comparison with the previous similar project data for time and cost variation. Altering the bid price quoted by the bidder internally as per the quantity variation anticipated through simulation. The limitation of this model was thatit considers historical data from previous projects, which contradicts to the fact that every project is unique with its own constraints.

\subsection{Based on Unascertained Model}

(An, et al., 2018) used Single index Unascertained model for preparation of the unbalanced bid detection model assuming the variation range of bidding unit price as reasonable and acceptable, relatively unbalanced and unbalanced and unacceptable. Theweightage of the factors was identified using Entropy Weight that was analyzed using the model.

\subsection{Fuzzy Logic Approach}

(Li, et al., 2020) 3 evaluation grades are decided as unit price varying up to $10 \%$, as ordinary bids, up to $20 \%$, its less unbalanced and up to $30 \%$, its unbalanced and is unacceptable. This model uses AHM and entropy both to identify weightage vectors for various items and fuzzy relation matrix for each bidder to calculate fuzzy comprehensive evaluation matrix. Limitation was that it does not consider the profit, loss or net value, significant in unbalancing.

\subsection{Bid Markup Distribution Index Graphs}

(Babak Nikpour, 2017) states that the as per engineer's estimate, the price distribution do not ensure an efficient cashflow, hence the bidders tend to redistribute their 
markups for efficient cashflow, ultimately ending up unbalancing. Themodel proposes a graphical method for detection of bid unbalancing by plotting Bid Markup Distribution Index on graph.

\section{UNBALANCED BIDDING MODEL}

\subsection{Gates Strategy}

Gates was the first one to propose the idea of unbalancing as a significant strategy to increase the probability of winning. He did not propose any mathematical model, but illustrated the concept of front-end loading and quantity error exploitation, which was widely practiced with time. Although gates did not realize the potential of use of sophisticated mathematical tool to accomplish unbalancing (Gates, 1959).

\subsection{Stark's Model}

Stark proposed a mathematical model based on linear programming solution and recognized constraints that impact item pricing.

1. All item prices add up to make tender price.

2. Item prices of some item are ruled by upper and lower limits that are arbitrarily decided or governed by other item's price.

3. The interim project payments made must be in proportion to the amount of work done. He stated the value of $\alpha$ (Stark's constant of proportionality) must be decided intuitively.

4. Objective was to maximize the present value

\subsection{Ashley And Teicholz's Model}

(Teicholz, 1977) intended to manipulate project cashflow by means of item price loading. Due tothe limited information available in initial stagesof project suggested three cashflow curves for decision making-

1. Earnings Curve - representing the value of the contractor's "work-in-place", derived from schedule of activity as per BOQ (David W. Cattell, 2007).

2. Payments Curve - derived from the earnings curve and adjusted as per retention expected to be held by client (David W. Cattell, 2007).

3. Cost Curve - representing the contractor's cash outflow, derived from the contractor's estimate, with schedule of activity and any lead or lag timing of the expected cash outflow (David W. Cattell, 2007).

The model included consideration of present value of the difference of the payment curve andcost curve, which can be further added up to identify Net Present Worth of the project. The model also included linear programming for front loading at the outset and end of the project such that the overall unbalanced bid retains the same simple cumulative value as the balanced bid, i.e., the total "earnings" of the project be kept the same (David W. Cattell, 2007). (Teicholzand \& Ashley, 1978) suggested another model with introduction to desirability index, with the argument that if the contractor can rank the items on the basis of their desirability, there is no need of linearprogramming model suggested before.

\subsection{Diekmann, Mayer And Stark's Model}

(Diekmann, et al., 1982) considered the factor ofrisk, and the risk that the quantity may vary during execution, ignoring other risks. The model facilitated that a contractor could utilize item price loading for not only maximizing their profit but also controlling their risk (albeit in the limited manner that they defined it) (David W. Cattell, 2007). The frame work help to compensate the risk to the contractor by ensuring profit of equivalent quantum. (Diekmann, et al., 1982) presented a model as the probabilistic equivalent of (Stark, 1974) deterministic model. They also formulated formula for mean and variance of the profit assuming it to be normally distributed.

\subsection{Cattell's Model}

(Cattell, 1984) model was based on Modern Portfolio theory, to manage the decisions regarding the combination of the risks and returns generated by item pricing. $\mathrm{He}$ argued that, as with the assessment of all other nature of investments, a rational contractor should not necessarily prefer a high-return / high-risk item price combination rather than a low-return / low-risk alternative combination (Cattell, 1984).

\section{FRAMEWORK DEVELOPMENT}

\subsection{Assumptions}

Certain assumptions were made for development of the model, which are discussed below:

1. The model completely ignores the probability of corruption.

2. Item Rate applies mostly to infrastructure projects; hence the duration of the projects was assumed to be beyond one year.

3. All bids are unbalanced, project performance and client's risk capability are affected by the quantum of unbalancing.

\section{Engineer's Estimate is balanced}

\subsection{Variables}

Net Present Value (NPV)- It is the calculation used to find today's value of a future stream of payments. Drawback of using an NPV analysis is that it makes assumptions about future events that may not be reliable (Fernando, 2020). The following formula is used to calculate NPV:

$$
\sum_{t=1}^{n} N V=\sum_{(1+i)} \frac{R_{t}}{t}
$$

where: $R t=N e t$ cash inflow-outflows during a 
"A Model for Detection and Prevention of Unbalanced Bid in the Public Work Procurement Process in India"

\author{
singleperiod $t$ \\ $i=$ Discount rate or return that could be \\ earned inalternative investments \\ $t=$ Number of timer periods
}

Item rate are mostly long-term project, henceimpact of NPV, will be significant.

Markup Distribution - As per the (CATTELL, etal., 2010) model, profit is one of the key considerations for unbalancing a bid, at the sametime judging whether the unbalanced bid received is a vulnerable threat or not. (Babak Nikpour, 2017) incorporated the idea of markup distribution for judging unbalancing.

Independent Variable - Inputs for the model are Engineer's estimate, BOQ, the item rates quoted by the bidder, the work packages or stages, as per which the payments will be made, the discount rates and other acceptable range of variation as per the risk of the client.

\subsection{Case Study}

The confidential data of project procurement in Indian Procurement system was inaccessible, hence a case study from another country was considered to demonstrate the model. The Case example represents a bid result for an asphalt concrete overlay project by California Department of Transportation in 2015 announced on their website (Caltrans 2015). It includes 24 bid line items; 15 of them are unit price and the remaining 9 are lump sum as shown in Table 1. Ten bidders submitted bids for the project.

\section{PROPOSAL FOR THE MODEL}

The model is based on simple mathematical logics and Microsoft Excel is the tool used.

\subsection{Stage 1}

Identification of true L1 bidder by analyzing the net values of various payment installments that will be made to the contractor stage wise. The bidder with least NPV will be considered the discount rate for current year and successive year was considered to be $12 \%$ and $13 \%$ respectively (Table 2).

\subsection{Stage 2}

Detection and remedy for Quantitative Error Exploitation unbalanced bid.

Step 1 - Outliers lying beyond upper limit using quartile range are identified and the outliers below the lower limits were ignored as they are not a threat to the project budget (Table 3).

Step 2 - Items whose quantities are susceptible to change are identified and those whose quantities are non-decisive like lumpsum, are ignored.

Step 3 - (Sensitivity Analysis) The items identified in previous stage are analyzed for theirimpact on the overall project budget if the quantities change and the project is awarded to the L1 bidder. This analysis is done via "What if' Data function in excel.

Table 4 provides percentage variation in the totalbid by the bidder, if the vulnerable item's quantity changes by $\pm 15 \%$, this range can be decided by the client and may input the allowable percentage deviation to analyze theimpact of quantity change of bid items. These percentage can be utilized to calculate the actual additional amount to performance security deposit.

\subsection{Stage 3}

This stage involves identification of front or back loaded bid.

Step 1 - Profit percentage calculation

The present value calculated for all the bidders were subtracted from the Engineer's Estimatepresent value, work package wise, and their percentage was calculated with respect to Engineer's Estimate. This percentage depicts whether the bid is front loaded or backloaded and is the quantum worth considering (Table 5).

Step 2 - Comparing Unbalanced with Balanced

The change of sign signifies variation in profit loading by the bidder as one moves along progressing work packages (Table 5).

1. negative to positive, the bid is front loaded.

2. positive to negative, the bid is back loaded.

3. If the bid changes sign more than once, the intensity of risk reduces as, to maintain the overall bid lowest the bidder has to compensate the high profits with minute loss. Multiple profit loss variation will keep the bid within the safe range set by the client.

4. The magnitude of profit or loss is important to consider as per the client's risk capability.

Based on the assumption that the cost distribution in Engineer's Estimate is balanced, cost distribution is calculated in percentage (Table 6). This distribution is then applied to other bids and are compared in their graphic format.

\section{Graph Analysis}

1. If the actual bid curve is above the balanced bid curve in initial payment slots, then it's a front-loaded bid.

2. If the actual bid curve is above the balanced bid curve in final payment slots, then it is a back loaded bid.

3. If the actual curve and the balanced bid are close, then the actual bid is nearly balanced.

\section{CONCLUSION}

The intension to develop the model was to detectand prevent unbalanced bid which is partial shareholder among various anomalies in public procurement for causing project cost escalation, poor execution and sometimes abandonment. The proposed model helps detection and prevention of Quantity Error Exploitation, Front loaded bid and Back loaded bid, by mitigating its impact on the project by providing figures that help in compensating the impact. The modelintends to fill the gap due to the absence of any legitimate model for unbalanced bid detection and prevention. Apart from the proposed model for prevention 
of unbalanced bid, there are other recommendations, that can be followed:

1. front loaded percent-wise payment schedule within client's safe limit, in the NIT floated, will help reduce risk of front loading by bidders to enhance their initial cashflow.

2. Cost-Plus Percentage Contract may reduce the risk of unbalancing but it compromises the scope of reducing cost of the project (Minimum cost for Owner).

3. Involve known pseudo bidders experienced in the concerned project execution hence use their bid for examining unbalancing.

4. Once L1 is selected, phasing or payment rescheduling, to reduce the risk ofunbalancing.

5. (Yuhan Jiang, 2019) propose use of cooperating project delivery methods such as design-build to protect owners' interests.

6. Engineers may improve estimating accuracy by reducing design errors or changes.

\section{LIMITATIONS}

The model also has certain limitation associated,as it does not consider collusive unbalanced bid. Also, the model does not provide a standard program but a methodology that can be applied to various projects with modifications as every project is unique. The input parameters may change from project to project, as a result, the operator needs understand the model, incorporate required changes and then apply the model, for detection of unbalanced bid. Most of the research relied upon secondary data available through internet access due to Global Pandemic. The research is limited to item rate contracts conducted usually for infrastructure project by Indian government and do not address unbalanced bidding in other contract forms.

\section{FUTURE SCOPE}

The scope of proposed model is limited to Item rate contracts, albeit increasing adoption of percentage-based contract and Design Build or EPC also suffers the anomaly of unbalancing. The research can be further explored by extending the scope to other procurement systems as well 
"A Model for Detection and Prevention of Unbalanced Bid in the Public Work Procurement Process in India"

Table 1. Case Study Work Packages

Bid- Description

item

Start date Finish date Unit Qty. Engineer

's item price
Engineer's estima te

(INR)

\begin{tabular}{|c|c|c|c|c|c|c|c|}
\hline & Road Construction & $1 / 1 / 2018$ & $5 / 31 / 2019$ & & & & \\
\hline & Work Package 1 & $1 / 1 / 2018$ & $3 / 23 / 2018$ & & & & \\
\hline 1 & Lead compliance plan & $1 / 1 / 2018$ & $1 / 22 / 2018$ & LS & 1 & $198,747.00$ & $198,747.00$ \\
\hline 2 & Construction area sign & $1 / 23 / 2018$ & $2 / 9 / 2018$ & LS & 1 & $220,830.00$ & $220,830.00$ \\
\hline 3 & Traffic control system & $2 / 12 / 2018$ & $3 / 2 / 2018$ & LS & 1 & $11,041,500.00$ & $11,041,500.00$ \\
\hline 4 & Portable changeable message sign & $3 / 5 / 2018$ & $3 / 23 / 2018$ & LS & 1 & $515,270.00$ & $515,270.00$ \\
\hline 6 & Prepare water pollution control program & $1 / 1 / 2018$ & $1 / 18 / 2018$ & LS & 1 & $147,220.00$ & $147,220.00$ \\
\hline \multirow[t]{2}{*}{5} & Management Job & & & LS & 2 & $736,100.00$ & $1,472,200.00$ \\
\hline & Work Package 2 & $3 / 26 / 2018$ & $5 / 30 / 2018$ & & & & \\
\hline 7 & Temporary drainage inlet protection & $3 / 26 / 2018$ & $5 / 16 / 2018$ & EA & 12 & $18,402.50$ & $220,830.00$ \\
\hline 8 & Street sweeping & $4 / 24 / 2018$ & $5 / 30 / 2018$ & LS & 1 & $1,104,150.00$ & $1,104,150.00$ \\
\hline \multirow[t]{2}{*}{5} & Management Job & & & LS & 2 & $736,100.00$ & $1,472,200.00$ \\
\hline & Work Package 3 & $6 / 1 / 2018$ & $9 / 5 / 2018$ & & & & \\
\hline 9 & $\begin{array}{l}\text { Remove yellow thermoplastic } \\
\text { (hazardouswaste) }\end{array}$ & stripe6/1/2018 & $7 / 5 / 2018$ & LF & 31800 & 22.08 & $702,239.40$ \\
\hline 10 & Remove thermoplastic traffic stripe & $6 / 12 / 2018$ & $7 / 13 / 2018$ & LF & 31700 & 13.25 & $420,018.66$ \\
\hline 11 & Remove thermoplastic pavement marking & $6 / 21 / 2018$ & $7 / 25 / 2018$ & $\begin{array}{l}\text { SQF } \\
\mathrm{T}\end{array}$ & 630 & 147.22 & $92,748.60$ \\
\hline 12 & Remove pavement maker & $7 / 26 / 2018$ & $9 / 5 / 2018$ & EA & 1330 & 73.61 & $97,901.30$ \\
\hline \multirow[t]{2}{*}{5} & Management Job & & & LS & 2 & $736,100.00$ & $1,472,200.00$ \\
\hline & Work Package 4 & $9 / 6 / 2018$ & $3 / 26 / 2019$ & & & & \\
\hline 13 & Cold plane asphalt concrete pavement & 9/6/2018 & $10 / 18 / 2018$ & $\begin{array}{l}\text { SQY } \\
\text { D }\end{array}$ & 9690 & 552.08 & $5,349,606.75$ \\
\hline 16 & Pre-paving inertial profiler & $9 / 20 / 2018$ & $10 / 18 / 2018$ & LS & 1 & $294,440.00$ & $294,440.00$ \\
\hline 21 & Tack coat & $10 / 4 / 2018$ & $11 / 1 / 2018$ & $\mathrm{t}$ & 33 & $51,527.00$ & $1,700,391.00$ \\
\hline 19 & Geosynthetic pavement interlayer (paving mat) & $10 / 18 / 2018$ & $11 / 29 / 2018$ & $\begin{array}{l}\text { SQY } \\
\text { D }\end{array}$ & 2650 & 570.48 & $1,511,765.38$ \\
\hline 17 & Hot-mix asphalt (type A) & $11 / 1 / 2018$ & $12 / 13 / 2018$ & $\mathrm{t}$ & 1920 & $8,833.20$ & $16,959,744.00$ \\
\hline 18 & Rubberized hot-mix asphalt (gap graded) & $11 / 15 / 2018$ & $12 / 27 / 2018$ & $\mathrm{t}$ & 4050 & $9,937.35$ & $40,246,267.50$ \\
\hline 20 & Data core & $12 / 28 / 2018$ & $1 / 11 / 2019$ & LS & 1 & $184,025.00$ & $184,025.00$ \\
\hline \multirow[t]{2}{*}{15} & Crack treatment & $1 / 14 / 2019$ & $2 / 11 / 2019$ & LNM & 3 & $331,245.00$ & $993,735.00$ \\
\hline & & & & I & & & \\
\hline 14 & Shoulder backing & $2 / 12 / 2019$ & $3 / 26 / 2019$ & $\mathrm{t}$ & 470 & $4,784.65$ & $2,248,785.50$ \\
\hline \multirow[t]{2}{*}{5} & Management Job & & & LS & 2 & $736,100.00$ & $1,472,200.00$ \\
\hline & Work Package 5 & $3 / 27 / 2019$ & $5 / 31 / 2019$ & & & & \\
\hline 22 & 4" Thermoplastic traffic stripe & $3 / 27 / 2019$ & $4 / 10 / 2019$ & LF & 63500 & 25.76 & $1,635,982.25$ \\
\hline 23 & Thermoplastic pavement marking & $4 / 11 / 2019$ & $5 / 2 / 2019$ & $\begin{array}{l}\text { SQF } \\
\text { T }\end{array}$ & 630 & 294.44 & $185,497.20$ \\
\hline 24 & Pavement marker (retroreflective) & $5 / 3 / 2019$ & $5 / 31 / 2019$ & EA & 1330 & 184.03 & $244,753.25$ \\
\hline 5 & Management Job & & & LS & 2 & $736,100.00$ & $1,472,200.00$ \\
\hline
\end{tabular}


"A Model for Detection and Prevention of Unbalanced Bid in the Public Work Procurement Process in India"

Table 2. Bid Summary and NPV

\begin{tabular}{lllllll}
\hline & Work Package 1 & Work Package 2 & Work Package 3 & Work Package 4 & Work Package 5 & NPV \\
\hline Engineer & 13595767.00 & 2797180.00 & 2785107.96 & 62797309.85 & 3131356.37 & 85106721.18 \\
\hline Bidder 1 & 13471366.10 & 4939231.00 & 4923404.85 & 58069170.18 & 4922098.76 & 86325270.89 \\
\hline Bidder 2 & 16822093.30 & 4549098.00 & 2196301.57 & 50468839.96 & 2851573.23 & 76887906.06 \\
\hline Bidder 3 & 8191922.93 & 971652.00 & 1619589.30 & 59998006.88 & 2069874.12 & 72851045.23 \\
\hline Bidder 4 & 7545025.00 & 802349.00 & 1156045.05 & 62659372.52 & 1874449.34 & 74037240.91 \\
\hline Bidder 5 & 11924820.00 & 5005480.00 & 5074084.52 & 64541703.99 & 5248718.71 & 91794807.22 \\
\hline Bidder 6 & 5830648.10 & 1560532.00 & 2325126.43 & 68445808.37 & 2657842.13 & 80819957.04 \\
\hline Bidder 7 & 15480183.00 & 4637430.00 & 5203122.85 & 63331959.47 & 5312948.32 & 93965643.64 \\
\hline Bidder 8 & 13912290.00 & 1928582.00 & 1764505.31 & 65134915.91 & 2395582.08 & 85135875.30 \\
\hline Bidder 9 & 16451835.00 & 3901330.00 & 2222249.10 & 61297945.80 & 2538079.31 & 86411439.21 \\
\hline Bidder 10 & 7581830.00 & 1472200.00 & 1610954.85 & 71212528.81 & 1990727.08 & 83868240.74 \\
\hline True L1 & (Bidder 3) & & & & 72851045.23 \\
\hline
\end{tabular}

Table 3. Outlier Identification

\begin{tabular}{|c|c|c|c|c|c|c|c|c|c|c|c|c|c|c|}
\hline $\begin{array}{l}\text { Bid itemDescription } \\
\text { number }\end{array}$ & Unit & Qty. & $\begin{array}{l}\text { Engineer' } \\
\mathrm{s} \text { item } \\
\text { price }\end{array}$ & B 1 & B 2 & $\begin{array}{l}\mathrm{B} \\
3\end{array}$ & $\begin{array}{l}B \\
4\end{array}$ & $\begin{array}{l}\mathrm{B} \\
5\end{array}$ & $\begin{array}{l}\text { B } \\
6\end{array}$ & $\begin{array}{l}\text { B } \\
7\end{array}$ & $\begin{array}{l}\text { B } \\
8\end{array}$ & $\begin{array}{l}\text { B } \\
9\end{array}$ & $\begin{array}{l}\text { B1 } \\
0\end{array}$ & $\begin{array}{l}\text { Number of bidder } \\
\text { who overpriced } \\
\text { the } \\
\text { item }\end{array}$ \\
\hline
\end{tabular}

\begin{tabular}{|c|c|c|c|c|c|c|c|c|c|c|c|c|c|c|c|}
\hline & Road Construction & & & & & & & & & & & & & & \\
\hline & Work Package 1 & & & & & & & & & & & & & & \\
\hline 2 & Construction area sign & LS & 1 & 0 & 0 & 0 & 0 & 0 & 1 & 0 & 0 & 0 & 0 & 0 & 1 \\
\hline 6 & $\begin{array}{ll}\text { Prepare } & \text { water } \\
& \text { pollution }\end{array}$ & LS & 1 & 0 & 0 & 0 & 0 & 0 & 1 & 0 & 0 & 0 & 1 & 0 & 2 \\
\hline
\end{tabular}

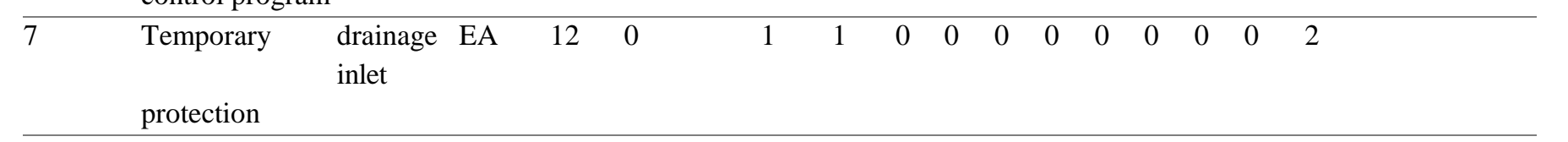

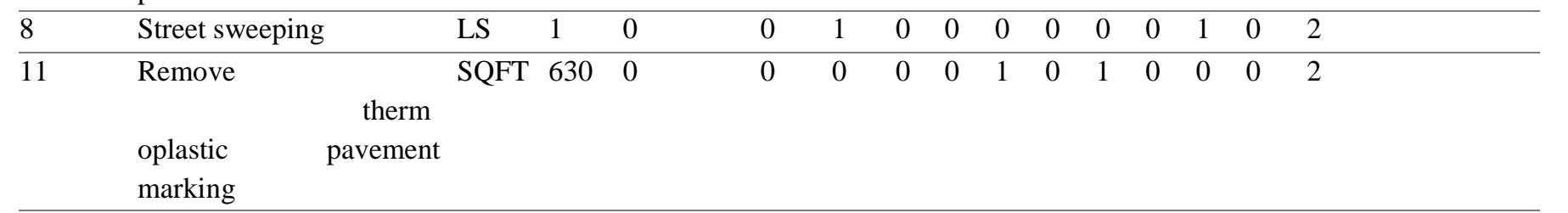

\begin{tabular}{lllllllllllllllll}
\hline 12 & Remove pavement maker & EA & 1330 & 0 & & 0 & 0 & 1 & 0 & 0 & 0 & 0 & 0 & 0 & 0 & 1 \\
\hline 16 & Prepaving inertial profiler & LS & 1 & 0 & & 0 & 0 & 0 & 0 & 0 & 0 & 0 & 1 & 0 & 0 & 1 \\
\hline 21 & Tack coat & $\mathrm{t}$ & 33 & 0 & 0 & 0 & 0 & 0 & 0 & 0 & 0 & 0 & 0 & 1 & 1 \\
\hline 19 & Geosynthetic & SQYD & 2650 & 0 & & 0 & 0 & 0 & 0 & 1 & 0 & 0 & 0 & 0 & 0 & 1
\end{tabular}
avement interlayer (paving mat)

\begin{tabular}{|c|c|c|c|c|c|c|c|c|c|c|c|c|c|c|c|}
\hline 18 & $\begin{array}{l}\text { Rubberized hot- } \\
\text { asphalt(gap graded) }\end{array}$ & & 4050 & 0 & 0 & 0 & 0 & 0 & 0 & 0 & 0 & 0 & 0 & 1 & 1 \\
\hline 20 & Data core & LS & 1 & 0 & 0 & 1 & 0 & 0 & 0 & 0 & 0 & 0 & 0 & 0 & 1 \\
\hline 15 & Crack treatment & LNMI & 3 & 0 & 0 & 0 & 0 & 0 & 0 & 0 & 0 & 1 & 0 & 0 & 1 \\
\hline \multirow[t]{2}{*}{14} & Shoulder backing & $\mathrm{t}$ & 470 & 0 & 0 & 0 & 0 & 0 & 0 & 0 & 0 & 0 & 0 & 1 & 1 \\
\hline & Work Package 5 & & & & & & & & & & & & & & \\
\hline 22 & $\begin{array}{l}\text { Thermoplastic } \\
\text { trafficstripe }\end{array}$ & $\mathrm{LF}$ & $\begin{array}{l}6350 \\
0\end{array}$ & 0 & 0 & 0 & 0 & 0 & 0 & 0 & 1 & 0 & 0 & 0 & 1 \\
\hline
\end{tabular}


"A Model for Detection and Prevention of Unbalanced Bid in the Public Work Procurement Process in India"

$\begin{array}{lllllllllllllll}\begin{array}{l}\text { Number } \\ \text { overpriced } \\ \text { by bidder }\end{array} & \text { of } & \text { items } & 0 & 1 & 3 & 1 & 0 & 4 & 0 & 2 & 2 & 2 & 3 \\ \end{array}$

Table 4. Sensitivity Analysis

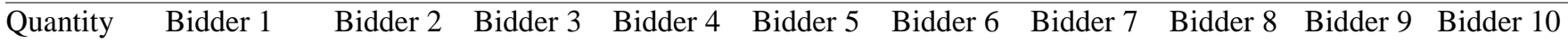

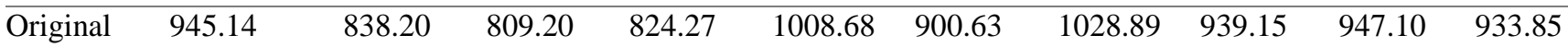

Temporary drainage inlet protection

\begin{tabular}{llllllllllll}
\hline 13.8 & $100.06 \%$ & $100.06 \%$ & $100.02 \%$ & $100.03 \%$ & $100.03 \%$ & $100.04 \%$ & $100.03 \%$ & $100.01 \%$ & $100.03 \%$ & $100.04 \%$ \\
\hline 12 & $100.00 \%$ & $100.00 \%$ & $100.00 \%$ & $100.00 \%$ & $100.00 \%$ & $100.00 \%$ & $100.00 \%$ & $100.00 \%$ & $100.00 \%$ & $100.00 \%$ \\
\hline 10.2 & $99.94 \%$ & $99.94 \%$ & $99.98 \%$ & $99.97 \%$ & $99.97 \%$ & $99.96 \%$ & $99.97 \%$ & $99.99 \%$ & $99.97 \%$ & $99.96 \%$ &
\end{tabular}

Remove thermoplastic pavement marking

\begin{tabular}{|c|c|c|c|c|c|c|c|c|c|c|}
\hline & 945.14 & 838.20 & 809.20 & 824.27 & 1008.68 & 900.63 & 1028.89 & 939.15 & 947.10 & 933.85 \\
\hline 724.5 & $100.01 \%$ & $100.00 \%$ & $100.02 \%$ & $100.02 \%$ & $100.02 \%$ & $100.02 \%$ & $100.02 \%$ & $100.01 \%$ & $100.02 \%$ & $100.01 \%$ \\
\hline 30 & $100.00 \%$ & $100.00 \%$ & $100.00 \%$ & $100.00 \%$ & $100.00 \%$ & $100.00 \%$ & $100.00 \%$ & $100.00 \%$ & $100.00 \%$ & $100.00 \%$ \\
\hline 35.5 & $99.99 \%$ & $100.00 \%$ & $99.98 \%$ & $99.98 \%$ & $99.98 \%$ & $99.98 \%$ & $99.98 \%$ & 99.999 & $99.98 c$ & $.99 \%$ \\
\hline
\end{tabular}

Remove pavement maker

\begin{tabular}{lllllllllll}
\hline & 945.14 & 838.20 & 809.20 & 824.27 & 1008.68 & 900.63 & 1028.89 & 939.15 & 947.10 & 933.85 \\
\hline 1529.5 & $100.02 \%$ & $100.02 \%$ & $100.03 \%$ & $100.02 \%$ & $100.00 \%$ & $100.02 \%$ & $100.01 \%$ & $100.02 \%$ & $100.02 \%$ & $100.02 \%$ \\
\hline 1330 & $100.00 \%$ & $100.00 \%$ & $100.00 \%$ & $100.00 \%$ & $100.00 \%$ & $100.00 \%$ & $100.00 \%$ & $100.00 \%$ & $100.00 \%$ & $100.00 \%$ \\
\hline 1130.5 & $99.98 \%$ & $99.98 \%$ & $99.97 \%$ & $99.98 \%$ & $100.00 \%$ & $99.98 \%$ & $99.99 \%$ & $99.98 \%$ & $99.98 \%$ & $99.98 \%$ \\
\hline Tack coat & & & & & & & & & & \\
\hline & 945.14 & 838.20 & 809.20 & 824.27 & 1008.68 & 900.63 & 1028.89 & 939.15 & 947.10 & 933.85 \\
\hline 37.95 & $100.23 \%$ & $100.32 \%$ & $100.30 \%$ & $100.35 \%$ & $100.28 \%$ & $100.31 \%$ & $100.18 \%$ & $100.23 \%$ & $100.00 \%$ & $100.47 \%$ \\
\hline 33 & $100.00 \%$ & $100.00 \%$ & $100.00 \%$ & $100.00 \%$ & $100.00 \%$ & $100.00 \%$ & $100.00 \%$ & $100.00 \%$ & $100.00 \%$ & $100.00 \%$ \\
\hline 28.05 & $99.77 \%$ & $99.68 \%$ & $99.70 \%$ & $99.65 \%$ & $99.72 \%$ & $99.69 \%$ & $99.82 \%$ & $99.77 \%$ & $100.00 \%$ & $99.53 \%$
\end{tabular}

Geosynthetic pavement interlayer (paving mat)

\begin{tabular}{lllllllllll}
\hline & 945.14 & 838.20 & 809.20 & 824.27 & 1008.68 & 900.63 & 1028.89 & 939.15 & 947.10 & 933.85 \\
\hline 3047.5 & $100.06 \%$ & $100.24 \%$ & $100.24 \%$ & $100.27 \%$ & $100.29 \%$ & $100.23 \%$ & $100.23 \%$ & $100.16 \%$ & $100.24 \%$ & $100.21 \%$ \\
\hline 2650 & $100.00 \%$ & $100.00 \%$ & $100.00 \%$ & $100.00 \%$ & $100.00 \%$ & $100.00 \%$ & $100.00 \%$ & $100.00 \%$ & $100.00 \%$ & $100.00 \%$ \\
\hline 2252.5 & $99.94 \%$ & $99.76 \%$ & $99.76 \%$ & $99.73 \%$ & $99.71 \%$ & $99.77 \%$ & $99.77 \%$ & $99.84 \%$ & $99.76 \%$ & $99.79 \%$ \\
\hline
\end{tabular}

Rubberized hot-mix asphalt (gap graded)

\begin{tabular}{|c|c|c|c|c|c|c|c|c|c|c|}
\hline & 945.14 & 838.20 & 809.20 & 824.27 & 1008.68 & 900.63 & 1028.89 & 939.15 & 947.10 & 933.85 \\
\hline 4657.5 & $105.68 \%$ & $105.01 \%$ & $107.03 \%$ & $107.89 \%$ & $105.99 \%$ & $107.87 \%$ & $105.43 \%$ & $106.43 \%$ & $106.14 \%$ & $107.90 \%$ \\
\hline 4050 & $100.00 \%$ & $100.00 \%$ & $100.00 \%$ & $100.00 \%$ & $100.00 \%$ & $100.00 \%$ & $100.00 \%$ & $100.00 \%$ & $100.00 \%$ & $100.00 \%$ \\
\hline 3442.5 & $94.32 \%$ & $94.99 \%$ & $92.97 \%$ & $92.11 \%$ & $94.01 \%$ & $92.13 \%$ & $94.57 \%$ & $93.57 \%$ & $93.86 \%$ & $92.10 \%$ \\
\hline Quantity & Bidder 1 & Bidder 2 & Bidder 3 & Bidder 4 & Bidder 5 & Bidder 6 & Bidder 7 & Bidder 8 & Bidder 9 & Bidder 10 \\
\hline Original & 945.14 & 838.20 & 809.20 & 824.27 & 1008.68 & 900.63 & 1028.89 & 939.15 & 947.10 & 933.85 \\
\hline \multicolumn{11}{|c|}{ Crack treatment } \\
\hline 3.45 & $100.16 \%$ & $100.18 \%$ & $100.19 \%$ & $100.20 \%$ & $100.19 \%$ & $100.18 \%$ & $100.09 \%$ & $100.26 \%$ & $100.19 \%$ & $100.16 \%$ \\
\hline 3 & $100.00 \%$ & $100.00 \%$ & $100.00 \%$ & $100.00 \%$ & $100.00 \%$ & $100.00 \%$ & $100.00 \%$ & $100.00 \%$ & $100.00 \%$ & $100.00 \%$ \\
\hline 2.55 & $99.84 \%$ & $99.82 \%$ & $99.81 \%$ & $99.80 \%$ & $99.81 \%$ & $99.82 \%$ & $99.91 \%$ & $99.74 \%$ & $99.81 \%$ & $99.84 \%$ \\
\hline \multicolumn{11}{|c|}{ Shoulder backing } \\
\hline & 945.14 & 838.20 & 809.20 & 824.27 & 1008.68 & 900.63 & 1028.89 & 939.15 & 947.10 & 933.85 \\
\hline 540.5 & $100.26 \%$ & $100.64 \%$ & $100.39 \%$ & $100.41 \%$ & $100.23 \%$ & $100.25 \%$ & $100.41 \%$ & $100.22 \%$ & $100.36 \%$ & $100.64 \%$ \\
\hline 470 & $100.00 \%$ & $100.00 \%$ & $100.00 \%$ & $100.00 \%$ & $100.00 \%$ & $100.00 \%$ & $100.00 \%$ & $100.00 \%$ & $100.00 \%$ & $100.00 \%$ \\
\hline 399.5 & $99.74 \%$ & $99.36 \%$ & $99.61 \%$ & $99.59 \%$ & $99.77 \%$ & $99.75 \%$ & $99.59 \%$ & $99.78 \%$ & $99.64 \%$ & $99.36 \%$ \\
\hline
\end{tabular}


"A Model for Detection and Prevention of Unbalanced Bid in the Public Work Procurement Process in India"

\begin{tabular}{lllllllllll}
\hline & 945.14 & 838.20 & 809.20 & 824.27 & 1008.68 & 900.63 & 1028.89 & 939.15 & 947.10 & 933.85 \\
\hline 73025 & $100.22 \%$ & $100.29 \%$ & $100.30 \%$ & $100.30 \%$ & $100.25 \%$ & $100.25 \%$ & $100.27 \%$ & $100.26 \%$ & $100.26 \%$ & $100.23 \%$ \\
\hline 63500 & $100.00 \%$ & $100.00 \%$ & $100.00 \%$ & $100.00 \%$ & $100.00 \%$ & $100.00 \%$ & $100.00 \%$ & $100.00 \%$ & $100.00 \%$ & $100.00 \%$ \\
\hline 53975 & $99.78 \%$ & $99.71 \%$ & $99.70 \%$ & $99.70 \%$ & $99.75 \%$ & $99.75 \%$ & $99.73 \%$ & $99.74 \%$ & $99.74 \%$ & $99.77 \%$ \\
\hline
\end{tabular}

Table 5. Bid Comparison

\begin{tabular}{lllllll}
\hline & $\begin{array}{l}\text { Work } \\
\text { Package1 }\end{array}$ & $\begin{array}{l}\text { Work } \\
\text { Package2 }\end{array}$ & $\begin{array}{l}\text { Work } \\
\text { Package3 }\end{array}$ & $\begin{array}{l}\text { Work } \\
\text { Package4 }\end{array}$ & $\begin{array}{l}\text { Work } \\
\text { Package5 }\end{array}$ & $\begin{array}{l}\text { (Profit } \\
\text { Percentage) }\end{array}$ \\
\hline Engineer & $0.00 \%$ & $0.00 \%$ & $0.00 \%$ & $0.00 \%$ & $0.00 \%$ & $0.00 \%$ \\
\hline Bidder 1 & $0.15 \%$ & $-2.52 \%$ & $-2.51 \%$ & $5.56 \%$ & $-2.10 \%$ & $-1.43 \%$ \\
\hline Bidder 2 & $-3.79 \%$ & $-2.06 \%$ & $0.69 \%$ & $14.49 \%$ & $0.33 \%$ & $9.66 \%$ \\
\hline Bidder 3 & $6.35 \%$ & $2.14 \%$ & $1.37 \%$ & $3.29 \%$ & $1.25 \%$ & $14.40 \%$ \\
\hline Bidder 4 & $7.11 \%$ & $2.34 \%$ & $1.91 \%$ & $0.16 \%$ & $1.48 \%$ & $13.01 \%$ \\
\hline Bidder 5 & $1.96 \%$ & $-2.59 \%$ & $-2.69 \%$ & $-2.05 \%$ & $-2.49 \%$ & $-7.86 \%$ \\
\hline Bidder 6 & $9.12 \%$ & $1.45 \%$ & $0.54 \%$ & $-6.64 \%$ & $0.56 \%$ & $5.04 \%$ \\
\hline Bidder 7 & $-2.21 \%$ & $-2.16 \%$ & $-2.84 \%$ & $-0.63 \%$ & $-2.56 \%$ & $-10.41 \%$ \\
\hline Bidder 8 & $-0.37 \%$ & $1.02 \%$ & $1.20 \%$ & $-2.75 \%$ & $0.86 \%$ & $-0.03 \%$ \\
\hline Bidder 9 & $-3.36 \%$ & $-1.30 \%$ & $0.66 \%$ & $1.76 \%$ & $0.70 \%$ & $-1.53 \%$ \\
\hline $\begin{array}{l}\text { Bidd } \\
\text { er10 }\end{array}$ & $7.07 \%$ & $1.56 \%$ & $1.38 \%$ & $-9.89 \%$ & $1.34 \%$ & $1.46 \%$ \\
\hline
\end{tabular}

Table 6. Comparing bidder's actual bid with their balanced version calculated on the basis of markup distribution of Engineer's Estimate

\begin{tabular}{|c|c|c|c|c|c|c|}
\hline & $\begin{array}{l}\text { Work Packag } \\
1\end{array}$ & $\begin{array}{l}\text { eWork Packag } \\
2\end{array}$ & $\begin{array}{l}\text { Work Packa } \\
3\end{array}$ & $\begin{array}{l}\text { geWork Packas } \\
4\end{array}$ & $\begin{array}{l}\text { eWork Packa } \\
5\end{array}$ & eNPV \\
\hline Engineer & 13595767 & 2797180 & 2785107.96 & 62797309.85 & 3131356.372 & 85106721.18 \\
\hline $\begin{array}{l}\text { Price distribution of engineer' } \\
\text { estimate }\end{array}$ & $\mathrm{s} 16 \%$ & $3 \%$ & $3 \%$ & $74 \%$ & $4 \%$ & $100 \%$ \\
\hline Balanced bidder 1 & 13790429.86 & 2837229.75 & 2824984.86 & 63696435.59 & 3176190.83 & $\begin{array}{l}86325270.8 \\
9\end{array}$ \\
\hline Actual bidder 1 & 13471366.10 & 4939231.00 & 4923404.85 & 58069170.18 & 4922098.76 & $\begin{array}{l}86325270.8 \\
9\end{array}$ \\
\hline Balanced bidder 2 & 12282814.35 & 2527054.38 & 2516148.15 & 56732930.06 & 2828959.11 & $\begin{array}{l}76887906.0 \\
6\end{array}$ \\
\hline Actual bidder 2 & 16822093.30 & 4549098.00 & 2196301.57 & 50468839.96 & 2851573.23 & $\begin{array}{l}76887906.0 \\
6\end{array}$ \\
\hline Balanced bidder 3 & 11637927.33 & 2394375.95 & 2384042.33 & 53754269.89 & 2680429.72 & $\begin{array}{l}72851045.2 \\
3\end{array}$ \\
\hline Actual bidder 3 & 8191922.93 & 971652.00 & 1619589.30 & 59998006.88 & 2069874.12 & $\begin{array}{l}72851045.2 \\
3\end{array}$ \\
\hline Balanced bidder 4 & 11827421.65 & 2433362.33 & 2422860.45 & 54629522.71 & 2724073.76 & $\begin{array}{l}74037240.9 \\
1\end{array}$ \\
\hline Actual bidder 4 & 7545025.00 & 802349.00 & 1156045.05 & 62659372.52 & 1874449.34 & $\begin{array}{l}74037240.9 \\
1\end{array}$ \\
\hline Balanced bidder 5 & 14664186.25 & 3016995.55 & 3003974.83 & 67732217.52 & 3377433.07 & $\begin{array}{l}91794807.2 \\
2\end{array}$ \\
\hline Actual bidder 5 & $11,924,820.00$ & $5,005,480.00$ & 5074084.52 & 64541703.99 & 5248718.71 & $\begin{array}{l}91794807.2 \\
2\end{array}$ \\
\hline Balanced bidder 6 & 12910958.03 & 2656288.06 & 2644824.08 & 59634254.66 & 2973632.21 & $\begin{array}{l}80819957.0 \\
4\end{array}$ \\
\hline Actual bidder 6 & 5830648.10 & 1560532.00 & 2325126.43 & 68445808.37 & 2657842.13 & $\begin{array}{l}80819957.0 \\
4\end{array}$ \\
\hline Balanced bidder 7 & 15010976.56 & 3088343.85 & 3075015.21 & 69334002.73 & 3457305.29 & 93965643.6 \\
\hline
\end{tabular}


"A Model for Detection and Prevention of Unbalanced Bid in the Public Work Procurement Process in India"

\begin{tabular}{|c|c|c|c|c|c|c|}
\hline & & & & & & 4 \\
\hline Actual bidder 7 & 15480183.00 & 4637430.00 & 5203122.85 & 63331959.47 & 5312948.32 & $\begin{array}{l}93965643.6 \\
4\end{array}$ \\
\hline Balanced bidder 8 & $13,600,424.36$ & $2,798,138.20$ & 2786062.03 & 62818821.66 & 3132429.05 & $\begin{array}{l}85135875.3 \\
0\end{array}$ \\
\hline Actual bidder 8 & 13912290.00 & 1928582.00 & 1764505.31 & 65134915.91 & 2395582.08 & $\begin{array}{l}85135875.3 \\
0\end{array}$ \\
\hline Balanced bidder 9 & 13804195.22 & 2840061.82 & 2827804.71 & 63760016.21 & 3179361.24 & $\begin{array}{l}86411439.2 \\
1\end{array}$ \\
\hline Actual bidder 9 & 16451835.00 & 3901330.00 & 2222249.10 & 61297945.80 & 2538079.31 & $\begin{array}{l}86411439.2 \\
1\end{array}$ \\
\hline Balanced bidder 10 & 13397920.21 & 2756475.19 & 2744578.83 & 61883477.91 & 3085788.60 & $\begin{array}{l}83868240.7 \\
4\end{array}$ \\
\hline Actual bidder 10 & 7581830.00 & 1472200.00 & 1610954.85 & 71212528.81 & 1990727.08 & $\begin{array}{l}83868240.7 \\
4\end{array}$ \\
\hline
\end{tabular}

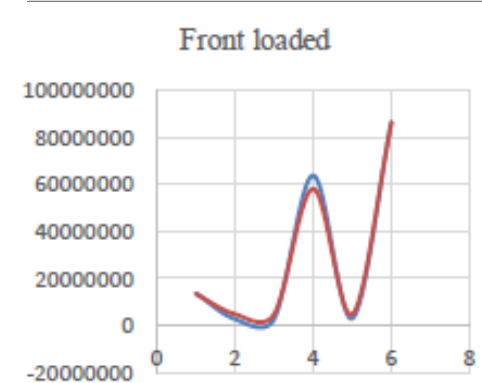

- BALANCED BIDDER 1

- ACTUAL BIDDER 1

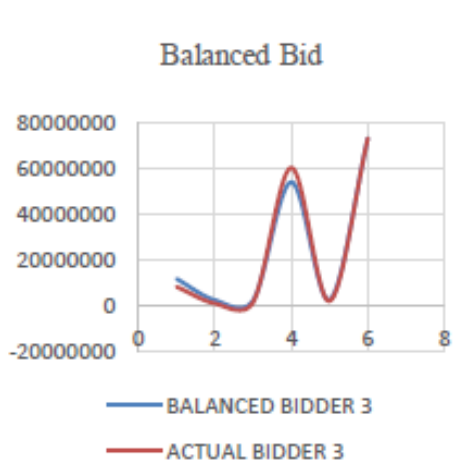

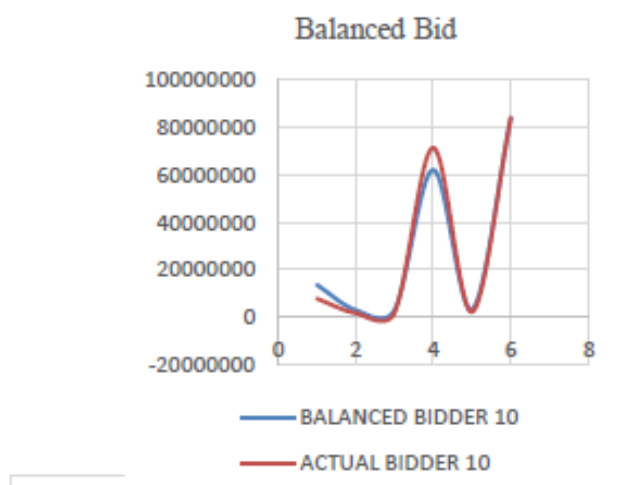

Slightly Unbalanced Bid

100000000

\section{REFERENCES}

1. Afshar, A. \& Amiri, H., 2010. A Min-max Regret Approach to Unbalanced Bidding in Construction. KSCE Journal of Civil Engineering, 14(5), pp. 653661 .

2. An, X. et al., 2018. Identification and Preventionof Unbalanced Bids Using the Unascertained Model. Journal of Construction Engineering and Management, 144(11), p. 05018013.

3. ARDITI, D. \& CHOTIBHONGS, R., 2009. Detection and prevention of unbalanced bids. Construction Management and Economics, Volume 27, p. 721-732 .

4. ASIAN DEVELOPMENT BANK, 2018. GUIDE ON BID EVALUATION, s.l.: Asian Development Bank.

5. Babak Nikpour, A. S. N. E., 2017. Detection Tool for Unbalanced Bids. Open Journal of Civil Engineering, Volume 7, pp. 409-422 .

6. Cattell, D., 1984. A model for item price loadingby building contractors. Department of Quantity Surveying, University of the Witwatersrand, Johannesburg.

7. CATTELL, D. W., BOWEN, P. A. \& KAKA, A. P., 2010. The risks of unbalanced bidding. Construction Management and Economics, Volume 28, p. 333-344 .

8. CENTRAL PUBLIC WORKS DEPARTMENT,
2019. CPWD WORKS MANUAL, New Delhi: The Authority of Director General, CPWD.

9. Christodoulou, S. E., 2009. A bid-unbalancing method for lowering a contractor's financial risk. Construction Management and Economics ,26(12), pp. 1291-1302.

10. David W. Cattell, P. A. B. a. A. P. K., 2007. A REVIEW OF UNBALANCED BIDDING MODELS IN CONSTRUCTION. Journal of Construction Engineering and Management, pp. 139.

11. Diekmann, J., Jr., R. M. \& Stark, R., 1982. Coping with uncertainty in unit price contracting. American Society of Civil Engineers, Journal of the Construction Division, 108(3), pp. 379-389.

12. Fernando, J., 2020. Net Present Value (NPV). [Online] Available at:

13. https://www.investopedia.com/terms/n/npv.asp

14. Gates, M., 1959. Aspects of competitive bidding. Connecticut Society of Civil Engineers.

15. Gopikrishnan, S. \& Paul, V. K., 2018. Validation and ranking of user requirement related building performance attributes and sub attributes for government residential buildings. Emerald Publishing Limited, 36(13), pp. 638-656.

16. Hyari, K. H., 2016. Owner's Countermeasures to Skewed Bidding in Construction Projects: Review of Current Practices and Proposal for New 
Countermeasures. American Society of Civil Engineers, pp. 04016053-1 - 04016053-9.

17. Hyari, K. H., 2017. The Controversy around Unbalanced Bidding in Construction: Seeking a Fair Balance. Journal of Professional Issues in Engineering Education and Practice, 143(1), pp. 04016015-1 - 04016015-10.

18. Kenley, D. R., (2003. Financing construction: Cash flows and cash farming. 1 ed. New York: Spon Press.

19. Li, H., Su, L., L.V., L. \& Xia, Q., 2020. Detecting unbalanced bidding to achieve economic sustainability using fuzzy logic approach. Construction Innovation () Emerald Publishing Limited, pp. 1471-4175 .

20. Malhotra, D., 2012. Study on Government Procurement Study for evidence basedcompetition advocacy, s.l.: s.n.

21. Manzo, F. A., 1997. The Impact of an Unbalanced Bid on the Change Order Process. GREYHAWK North America, LLC , pp. 1-8.

22. Ministry of finance, D. о. e., 2019. Manual for Procurement of Works, s.l.: Government of India.

23. Mittal, Y. K. et al., 2020. Delay factors in construction of healthcare infrastructure projects: a comparison amongst developing countries. Asian Journal of Civil Engineering, pp. 1-13.

24. Mittal, Y. K., Paul, V. K. \& Sawhney, A., 2019. Methodology for estimating the cost of delay in architectural engineering projects: case of metro rails in India. Journal of The Institution of Engineers (India): Series A, 100(2), pp. 311-318.

25. Nassar, K., 2003. Using Spreadsheets to Optimally Unbalance a Construction Bid. Clemson, South Carolina, ASC Proceedings of the 39th Annual Conference Clemson University.

26. Paul, V. K., Khursheed, S. \& Singh, R., 2017. Comparative study of construction technologies for underground metro stations in India. International Journal of Research in Engineering and Technology, 6(3), pp. 55-63.

27. Paul, V. K. \& Seth, V., 2017. Benchmarking and objective selection of technologies for housing in India using quality function deployment. Journal of Construction in Developing Countries, Volume 22, pp. $63-78$
28. Polat, G., Turkoglu, H. \& Damci, A., 2019. A Grading System-based Model for Detecting Unbalanced Bids during the Tendering Process. Periodica Polytechnica Architecture, 50(2), p.139147.

29. Prajapati, R. R. \& Bhavsar, P. J. J., 2017. Unit Quantity Contract as a Mitigation of Unbalanced Bidding. International Conference on Re-search and Innovations in Science, Engineering \&Technology, Volume 1, p. 157-162.

30. Remon F. Aziz, Y. M. A., 2019. Integration between different construction bidding models to improve profitability and reduce prices. Alexandria Engineering Journal, pp. 1110-0168

31. Sake Venkatesh1, S. V. R., 2017. EvaluationModel for Unbalanced Bidding in Construction Industry. International Journal of Engineering Science and Computing, 7(5), pp. 12520 - 12524

32. Shumank Deep, D. S. S. A. A., 2017. A Review of Contract Awards to Lowest Bidder in Indian Construction Projects via Case Based Approach. Open Journal of Business and Management, Volume 5, pp. 159-168.

33. Skitmore, M. \& Cattell, D., 2013. On being balanced in an unbalanced world. Journal of the Operational Research Society, 64(1), pp. 138146.

34. Stark, R., 1974. Unbalanced highway contract tendering. Operational Research Quarterly, 25(3), pp. 373-388.

35. Teicholzand, P. \& Ashley, D., 1978. Optimal bid prices for unit price contract. American Societyof Civil Engineers, Journal of the Construction Division, Volume 104, pp. 57-67.

36. Teicholz, D. A. a. P., 1977. Pre-estimate cash flow analysis. Journal of the Construction Division, American Society of Civil Engineers, 103 (C03), pp. 369-379.

37. THE WORLD BANK, 2016. PROCUREMENT IN INVESTMENT PROJECT FINANCING

38. Goods, Works, Non-Consulting and Consulting Services, s.1.: THE WORLD BANK .

39. Yuhan Jiang, Y. B. S. H. T. L., 2019. Probability of Failure in Infrastructure Project Unbalanced Bidding. s.l., Associated School of Construction. 